\title{
El problema de hablarte: tensiones y paradojas en Amado Señor de Pablo Katchadjian ${ }^{1}$
}

\author{
Lucas Comando \\ Profesor de Literatura \\ Universidad Católica Argentina \\ https://orcid.org/0000-0002-6683-5567 \\ comandolucas@gmail.com \\ Fernando Baroli \\ Licenciado en Letras \\ Universidad Católica Argentina \\ https://orcid.org/0000-0003-4698-3500 \\ fernandobaroli@gmail.com
}

\section{Resumen}

A través de una de las voces de un presunto diálogo epistolar con el Amado Señor, Pablo Katchadjian construye un entramado de tensiones que esboza la búsqueda de un personaje por conocer y alcanzar a su interlocutor. Son estas tensiones, tanto temáticas como del orden de lo formal, las que aportan una perspectiva profunda al texto y lo proyectan hasta la paradoja. El presente artículo se propone profundizar en esas tensiones en busca de los elementos que les dan sustento y que permiten rastrear las huellas íntimas de la identidad del personaje que escribe y se interpreta en su escritura.

Palabras clave: escrituras del yo; intimidad; Katchadjian; paradoja; tensiones.

\section{The predicament of talking to you: tensions and paradoxes in Amado Señor by Pablo Katchadjian}

\section{Abstract}

Through one of the voices of an alleged epistolary dialogue with the Beloved Lord [Amado Señor], Pablo Katchadjian builds a patchwork of tensions that outlines the

${ }^{1}$ Procedencia del artículo: Este artículo fue producido exclusivamente para la presente publicación. 
search of a character to know and reach his interlocutor. These tensions, both thematic and formal, bring a deep perspective to the text and project it to a paradox. This article aims to delve into these tensions in search of the elements that give them sustenance and that allow us to look for the intimate traces of the identity of the character who writes and interprets himself in his writing.

Keywords: writings of self; intimacy; Katchadjian; paradox; tensions.

Recibido: 11 de abril del 2021. Aprobado: 09 de mayo del 2021

Artículo de reflexión

https://doi.org/10.25100/poligramas.v0i53.11499

¿Cómo citar este artículo en MLA? - How to quote this article in MLA? Comando, Lucas y Fernando Baroli. "El problema de hablarte: tensiones y paradojas en Amado Señor de Pablo Katchadjian" Poligramas 53 (2021): e.2211499. Web. Fecha de acceso (día, mes en mayúscula y abreviado, y año).

Amado Señor, de Pablo Katchadjian, presenta al lector una sucesión de cartas que tienen como destinatario a una figura compleja, la del Amado Señor, quien no solo muta en su vocativo según el texto avanza (Amado Beso, Amado Murciélago...), sino que se va construyendo progresivamente en la escritura. La elección del género resulta particular: hay una estructura epistolar, es cierto, pero en su carácter unidireccional hay también un cruce genérico con la reflexión íntima, con el diario que no busca una respuesta concreta y a la vez la encuentra en el devenir de la propia escritura. Amado Señor retoma el tópico literario de la comunicación del individuo con su dios, con su creador, con una entidad que le resulta superior, atractiva y misteriosa.

La particularidad del destinatario acarrea cuestionamientos acerca del lenguaje y de las posibilidades de la comunicación: el personaje-emisor se pregunta cómo habrá de invocar a su interlocutor, cómo habrá de conocerlo, cuáles serán sus nombres, cómo es; en fin, una conversación en la que quien 
escribe crea a quien lo lee, entre otras cosas. La escritura se torna, entonces, en una reflexión sobre el lenguaje: mientras se escribe se comprende y porque se escribe se crea. "Te hablo a vos y sé que te estoy hablando a vos, aunque no existas. Porque cuando te hablo existís. No porque piense que yo soy tu creador. Es al revés: yo te hablo, eso te hace existir y eso me crea a mí. Me crea una y otra vez. Si dejara de hablarte dejaría de ser creado. ¿Y qué quedaría de mí?” (Katchadjian 12).

El destinatario se convierte en un reflejo del yo que escribe, quien da cuenta de su proceso de pensamiento para intentar concebirlo y, al tiempo que crea, se pregunta por cómo seguir acercándose y conociéndolo, hasta llegar a la paradoja y a la redundancia.

Amado señor, por sus afinidades genéricas, nos enfrenta a ciertas figuras literarias cargadas por la historia. Así, es casi imposible realizar una lectura que no remita a otros textos en o desde los que resuena: las Confesiones de San Agustín, aunque también podríamos mencionar la Carta al padre de Kafka -ambas obras referidas por el propio autor en una entrevista con Darío Sztajnszrajber-. Por un lado, en las Confesiones, San Agustín elige también abordar la comunicación desde la pregunta:

Pero enseñadme, Señor, y haced que entienda si debe ser primero el invocaros que el alabaros, y antes el conoceros que el invocaros.

Mas ¿quién os invocará sin conoceros?, porque así se expondría a invocar otra cosa muy diferente de Vos, el que sin conoceros os invocara y llamara. $\mathrm{O}$ decidme, si es menester antes invocaros, para poder conoceros.

Mas ¿cómo os han de invocar, sin haber antes creído en Vos?, y ¿cómo han de creer, si no han tenido quien les predique y les dé conocimiento de Vos? (Agustín de Hipona, I, I).

Esta reflexión aparece también en Amado Señor. De algún modo, la pregunta por la invocación y el conocimiento de su interlocutor abre una suerte de diálogo y sortea el obstáculo de la comunicación. La pregunta abierta, en ambos 
casos, es reflexiva, vocativa, y ocupa el espacio de la respuesta que no será dada en forma explícita.

Asimismo, la relación -genérica, insistimos- que Amado Señor entabla con el texto de Agustín de Hipona nos coloca frente a otro aspecto de la obra: en varios sentidos, Amado Señor nos resulta una obra de carácter espiritual. Si bien es innegable la inscripción del texto de Katchadjian en el campo de la ficción, resulta evidente cierto acercamiento genérico a una escritura espiritual que se busca al emular determinados mecanismos y estructuras propios de la ficción testimonial. Katchadjian piensa también la escritura como un ejercicio de traducción: una traducción a la contemporaneidad que permite incorporar el texto a un momento actual de la tradición.

A mí lo que me gusta no es tanto distanciarme como ir y volver. Y la literatura es ideal para eso. Para mí no hay mucha diferencia, al leer, entre libros de un lugar y otro, o de una época $u$ otra, no porque sea lo mismo sino porque pueden ser experiencias de lectura intensas que logran correrme del lugar en el que estoy pensando o sintiendo. (...) Después ocurre también que uno, por inclinación personal, siente contemporaneidad en lugares raros, y al final, en la lectura, todo lo que no se vuelve de museo se vuelve contemporáneo. Así que sí, uno se arma su propia contemporaneidad yendo y volviendo. Después escribe lo que le sale" (Contré párr. 15).

Lo que separa a Katchadjian de una lectura desde un plano religioso es lo mismo que coloca a San Agustín tan decididamente en ese lugar: el contexto de producción y la tradición en la que se inscribe cada texto. En relación con esto último, Amado Señor exige al lector contemporáneo una amplitud en su abordaje propio de la autoficción. El pacto de lectura que se establece resulta ambiguo (Musitano 104). Es este un claro rasgo vanguardista en la escritura de Katchadjian: desconocemos como lectores a qué estamos accediendo con esta lectura de frontera, al mismo tiempo en el plano de la ficción y en el de la representación de la propia intimidad del yo que escribe, del personaje.

Por motivos similares a los enunciados anteriormente, podríamos también considerar Carta al padre como un texto fronterizo. Si bien tradicionalmente el 
texto nos suele remitir a la tipología confesional y autobiográfica, en el discurrir del relato la voz se disloca: frente a los recuerdos vívidos de aquellos tormentos de la infancia, de los actos despóticos del padre, aparece la voz del Kafka adulto que se juzga, que actúa de exégeta de sí mismo con implacable rigor y frialdad. El texto ahonda en la descripción detallada de un yo pasado que fue anulado, pero la voz que lo recupera vacila: responsabiliza a Kafka para luego eximirlo, culpabiliza al padre, pero luego lo justifica y aclara que sólo actuó acorde a su naturaleza. Carta al padre revela el intento por establecer una comunicación con un narratario que acaba siendo demasiado imponente, demasiado voraz y aplastante. Ese intento por combatir el miedo expresado en las primeras líneas resultará trunco y la posibilidad de una lectura que habilite la ficción aparece como resultado de la empresa fallida. Si bien el texto se perfila como el más genuino relato de expiación, acaba por imponerse el tenor literario que tiñe el texto de ambigüedades y variadas manipulaciones narrativas -desde la 'niebla' que no le permite recordar ciertos sucesos hasta las comparaciones explícitas con sus propios textos literarios-:

The very idea of guilt and forgiveness upon which the letter is built is being tossed around until it has lost any specific meaning. If it is the privilege -and the basic dubiousness- of modern literature to question by thought and linguistic processes any accepted standards, then a passage like this is apt to question the father-son relationship to a degree where there is nothing left but two masks grinning at each other in utter despair: a Kafka commentary on the alienation that governed his life (Politzer 178).

El final de la extensa carta de Kafka es la culminación de esta ambigüedad: la voz vacilante, que por momentos sentencia con la misma severidad del padre, asume en un último gesto de desdoblamiento el rol paterno del que se esperaba respuesta. Kafka imagina y relata cómo su padre hubiera resquebrajado cada uno de los argumentos y de las meditaciones que la voz discursiva fue construyendo a lo largo del relato. Kafka le contesta a Kafka, el padre es ya finalmente una figura inasible, un producto de la pluma de quien escribe. La voz, unívoca al comienzo, ha desembocado fatalmente en una pantomima barroca y por eso el cierre solo 
puede tomar la forma de una tregua que le revela al yo desmembrado los límites de lo narrable:

Como es natural, las cosas no pueden encajar unas con otras en la realidad como encajan las pruebas en mi carta, la vida es algo más que un rompecabezas; pero con la corrección que resulta de esa objeción, una corrección que no puedo ni quiero exponer con detalle, se ha llegado, a mi juicio, a algo tan cercano a la verdad que nos puede dar a ambos un poco de sosiego y hacernos más fáciles la vida y la muerte (Kafka 15).

Dicho esto, podemos señalar que cierta ambigüedad genérica -o la falta de inscripción clara en un género determinado-, la pregunta frente a la naturaleza de la invocación, la desigualdad que marca la construcción del enunciatario -el Amado Señor- con el personaje que escribe, entre otras cosas, sitúan al texto en un complejo juego de tensiones que se cimentan sobre algunos binarismos. Así, la tensión es clara -y ambigua, al mismo tiempo- entre creador y criatura, entre enunciador y enunciatario, entre pactos posibles de lectura. Pero estas tensiones exceden con creces lo formal y aparecen también tematizadas en el texto. La intención del presente artículo es la de establecer un recorrido que explore esas tensiones y nos permita profundizar en ellas.

La primera de estas tensiones presentes en el relato está encarnada por el propio sujeto: el enunciador que escribe el texto en la ficción, quien dice yo y pronuncia el vocativo que encabeza cada uno de los fragmentos. No es la intención del presente artículo profundizar en la relación que existe entre este sujeto enunciador y la figura real del autor, por lo que nos inclinaremos por la postura de Paul de Man, que ve en esta polaridad -ficción, no ficción- algo del orden de lo indecible (114). En otros textos, como es el caso de las Confesiones, la presuposición de un autor empírico que se lee en y con el texto permite la lectura de una búsqueda inmanente -lo que implicaría una lectura testimonial-, mientras que el abordaje de Katchadjian requiere -por motivos contextuales de orden histórico- una inclusión de su obra en el plano estrictamente literario y en el de la circulación de las obras literarias. 
Si bien partimos de la base de una relación epistolar, solo accedemos, como lectores, a una sola de las voces: la de quien escribe estas cartas e invoca al Amado Señor. Esta relación crea, indefectiblemente, una multiplicidad de desigualdades, no siempre en el mismo sentido o en la misma dirección. Primero, tenemos el hecho de que quien escribe monopoliza el discurso: el emisor es siempre el mismo. De este modo, conocemos a quien escribe por sus palabras y son esas mismas palabras las que configuran el conocimiento que tenemos sobre el destinatario. Ambos personajes del texto existen únicamente en el discurso de uno de los dos.

Pero, al mismo tiempo, es la naturaleza de ambos personajes lo que entra en tensión con este hecho: quien escribe es la criatura que habla con su creador. El personaje-escritor es consciente de la paradoja: él se siente inferior, se siente criatura frente a su interlocutor; pero al mismo tiempo reconoce estar creándolo en la escritura. Es esta asimetría ontológica la que cimenta las bases de la relación enunciador-enunciatario que se da, entonces, como una búsqueda, un intento de conocer a quien se escribe a través del acto mismo de escribirle. El personajeescritor buscará conocer a su interlocutor en el mismo acto de esta interlocución: "No busco, hablo, y así busco" (29). Esta paradoja aparece en el texto de muchas maneras como un obstáculo discursivo que el personaje reconoce y esquiva con los recursos que tiene a mano, a veces mencionando la paradoja como tal -"La paradoja es que al monstruo lo crea uno mismo hablándole" (51)- y, otras veces, abriendo el texto hacia digresiones narrativas que parecen alejarlo de su objetivo, como sucede, por ejemplo, con la narración que el gitano hace del robo de la bolsa de oro, o la de la artista que prepara una instalación, por mencionar solo algunas de ellas.

El personaje-escritor, a su vez, se desdobla en un rol dual: produce el texto al que accedemos y, al mismo tiempo, es quien lo interpreta en tanto discurso. En definitiva, el texto que se produce -el que el personaje escribe, el que Katchadjian publica- es una interpretación que el personaje-escritor hace de su propio discurso, idéntico mecanismo a lo que se pone en juego en Carta al padre y la función de la voz en ese texto, como apuntamos anteriormente. Si el objetivo del 
texto es construir y entender al enunciatario, podemos reconocer esta interpretación en dos niveles: se interpreta al enunciatario como personaje y se interpreta el texto como totalidad en tanto prefiguración de ese enunciatario que nunca se termina de aprehender. Esto último redunda aún más profundamente en el motivo de la asimetría ontológica entre quien escribe y su enunciatario.

Esta desigualdad entre enunciador y enunciatario no solo influye en la construcción que el personaje-escritor hace de su interlocutor, sino que es rastreable en varios niveles del texto. Una lectura de Amado Señor inaugura diversos interrogantes, como hacia dónde va el texto, cuál es su dirección, o si es o no preciso en este caso hablar siquiera de narración. Luego de las primeras cartas, el lector se encuentra con un relato que no avanza con una narración lineal: el método de la pregunta retórica y de la indagación introspectiva parece no hacer más que dar rodeos procurando nunca invadir o afrontar de manera directa el problema que lo vuelca a la escritura, que no es otra cosa que la relación con su enunciatario. La distancia prudencial entre el enunciador y el tema que está procurando tratar parece dar cuenta de la conciencia de esa complejidad. La dirección del texto es, entonces, circular, pues hay una mínima cantidad de sentido que el enunciador inyecta en momentos muy concretos del relato, como si los círculos lograran aprisionar brevemente el tema -en concreto, el Amado Señor-, hasta que aparezca una nueva digresión que nos devuelva a la dinámica textual instalada: la de una aparente digresión constante. La narración está descartada de plano por la propia voz en el texto: "Me cansé de narrar, que es seducir, que es como estar en una feria de comidas y artesanías encantando a los que pasan por delante de uno. $Y$ confío en que hablarte directamente por un rato me va a hacer sentir de nuevo el deseo de seducir y encantar en la feria" (55).

Es al Amado Señor a quien se le habla, pero ¿sobre qué?, ¿cuál es el tema de las cartas que integran el texto? La sensación es la de una falta de gravedad que unifique y ordene los fragmentos que se suceden con un encadenamiento semántico, pero de ningún modo progresivo. Esto provoca una liviandad constante que no se suple con el encabezado que alude al enunciatario de cada uno de los fragmentos ni con ese encadenamiento. De algún modo, el relato no tiene centro. 
Como sucede con la esfera de Pascal (Borges 20), el centro del relato está en todas partes y, al mismo tiempo, resulta inabarcable. El tema del texto así lo exige: si entendemos la escritura del personaje que narra como una búsqueda cuyo objetivo es conocer a su enunciatario -y a esto como el tema central del texto-, se deduce la paradoja que esto acarrea. Existen solo dos posibilidades frente a un tema que resulta inabarcable: o bien un texto infinito, o bien un texto que no tenga centro, que solo busque rodear su objetivo, soslayarlo. Naturalmente, la opción que Katchadjian toma en esta obra es la segunda. La secuencia del vocativo cambiante abona un poco esta perspectiva: incapaz de hablar a esa totalidad que reconoce como tal, el mecanismo es el de la individualización en un listado: "Amada Bola, Amado Origen, Amada Nube: todo da lo mismo. Amada Secuencia, Amada forma..." (21). Resulta particularmente complejo encontrar en un solo ejemplo textual algo que sintetice esta idea de la falta de centro.

Sin embargo, si miramos a través de algunos fragmentos, vemos la ausencia de un avance o, en todo caso, la recurrencia de una misma pregunta. Esto se hace particularmente claro si observamos las diferentes digresiones narrativas que el personaje coloca dispersas en el texto; parece que va a alejarse de la conversación con el Amado Señor, pero siempre vuelve al mismo punto. Así, al narrar un episodio de la infancia sobre un vestido de gasa, concluye: "Pienso que vos sos ese vestido de gasas superpuestas y que yo te sigo hipnotizado" (19); o bien, al narrar su encuentro con un gitano que le obsequia un cuchillo, cierra la historia diciendo "hablaba con el cuchillo como yo hablo con vos" (148). Todo contenido abordado lo devuelve al Amado Señor, como si no hubiera forma de salir de esa dinámica. Al mencionar a los escarabajos y su masticación, también vuelve a él: "lo mismo me pasa con el sonido de tu masticación" (35). La enumeración podría seguir y casi cualquier fragmento permitiría ilustrar esto.

En el mismo sentido en que decimos que el texto carece de un centro reconocible como tal, surge la pregunta por el contenido. El personaje busca en la escritura al Amado Señor -“...no busco, hablo, y así busco” (29)-, pero ¿qué es lo que le dice en ese itinerario?, ¿de qué le habla? La pregunta por el Amado Señor colma el texto en su totalidad, nada queda por fuera de esa pregunta; es decir que 
todo lo que el personaje-escritor pone en su discurso orbita esa pregunta. "El problema de hablarte directamente es que tu fuerza centrípeta se vuelve demasiado potente y todo lo absorbés: no queda nada fuera de lo que se te dice. Todo va hacia vos, como siempre, pero además va solamente hacia vos" (32).

Del mismo modo que el texto -la búsqueda- no agota la pregunta, sí sucede lo contrario: la pregunta agota el recurso del texto, lo acapara. Por esto es natural que el personaje-escritor reconozca nuevamente otra tensión, otra paradoja: la del contenido. Si el tema es la relación que se desenvuelve en la escritura, en la emulación de un diálogo, ¿cuál es el contenido de ese diálogo?

Te hablé de contenido y algo me preocupó. Porque yo te hablo sobre nada, sólo por hablarte, y eso sería sin contenido, pero a la vez me doy cuenta de que no quiero decirte cualquier cosa: no quiero hablarte de lo que comí, de lo que me molestó, de lo que pensé, de lo que me pasó en general: quiero decirte cosas que me aseguren tu atención, y sé que todo eso vos ya lo sabés, porque yo ya lo sé. Pero si quiero decirte ciertas cosas y otras no, ¿cómo entonces podría no pensar en términos de contenido? Esto me preocupó, como te decía, pero ahora que lo veo y lo pienso veo y pienso que en realidad te dije bien: no hay contenido, porque lo que digo va apareciendo, y el contenido es algo que está de antes y se pone en un lugar para que lo contenga, algo ya conocido, no algo que se va descubriendo. Y cuando yo te hablo no hay nada de antes, nada preparado, nada que te dé forma para llenarte de cosas que traigo. Lo que hago es ponerme en cierta posición que hace que yo pueda decir cierto tipo de cosas que sé que hacen que me escuches (81-82).

El personaje-escritor menciona aquí una cierta posición que habilita su discurso. Es consciente de que el contenido no es lo que le interesa, sino la forma que toma ese contenido, el rol que él ocupa en esa comunicación y, en definitiva, ese discurrir que no es otro que el de la búsqueda. El texto en sí es un itinerario circular que rodea la figura de su enunciatario. Hablar de un tema en particular que no sea este sería divagar y no es algo que el personaje-escritor se permita. Incluso las pequeñas digresiones narrativas que están salpicadas por el texto aunque se hacen más frecuentes hacia el final- terminan por desembocar en la 
figura del Amado Señor, se resuelven también en la órbita de la misma y constante pregunta.

Como hemos presentado hasta ahora, Amado Señor se encuentra atravesado por una pluralidad de paradojas: la relación desigual entre el enunciador y el enunciatario, la intención de una búsqueda que se intenta, pero se sabe imposible -"Te sigo cuando trato de no seguirte; cuando trato de seguirte me pierdo; cuando me pierdo descubro de repente que estoy siguiéndote" (94)-, la problematización sobre el contenido de la comunicación con el Amado Señor, entre otras. La paradoja es, en definitiva, una de las formas de la tensión. Quizás es el modo que Katchadjian, en este texto al menos, prefiere. Todos los fragmentos epistolares del texto incluyen, de un modo $u$ otro, una paradoja. Esto, creemos, está fundamentado en diversos elementos presentes en el texto, pero que, en su totalidad, se desprenden de una sola cosa: la relación ontológica que el personaje-escritor establece con su interlocutor -a quien crea en su escritura-. La paradoja, entonces, debe ser infinita, no debe agotarse en sí misma. Es por esto que la tensión en el texto es un asunto axial: no puede resolverse. La tensión debe ser infinita, como lo es el interlocutor que el personaje-escritor construye.

Amado Señor es, en muchos sentidos, un texto sobre la relación entre dos entidades, una que escribe y se nombra a sí misma, y otra a la que se le escribe y se nombra en la propia escritura. Este discurso confesional y dialógico con un ser metafísico -un otro, un absoluto, una entelequia superior- no puede ser sino una escritura del yo. Volvemos, a riesgo de caer en la redundancia, a recurrir a la paradoja como concepto: si el personaje-escritor, quien enuncia, es consciente de que está creando a su interlocutor, al mismo tiempo lo es de su ser criatura. "Cuando se dice 'creo en dios' lo que casi se está diciendo es que uno se está creando y recreando a sí mismo a través tuyo. Es un juego de palabras bobo y revelador de una especie de confusión que parece haber" (49). Pensar esta idea desde la paradoja nos permite abordar quizás otra de las intenciones -a la vez oculta, a la vez expuesta- del personaje en su escritura, en su acto del lenguaje: entrar en diálogo con su creador es crearse. El diálogo con un ser inasible o inabarcable -nunca inefable del todo- es un acto fundador de un diálogo con la 
propia identidad, un diálogo del orden de lo íntimo. Testimonio de esto último es, en forma redundante, la elección genérica de Katchadjian: las cartas a un enunciatario -a quien, no podemos dejar de subrayar, se alude como «amado»implican una enunciación que parte de la subjetividad y buscan un efecto en el lector que recrea el acceso a un discurso íntimo, un diálogo que no lo incluye en sus planes y que lo recibe como a un tercero. Este acceso de simulada lateralidad refuerza la sensación que se tiene de un discurso personal, íntimo y, sobre todo, auténtico.

Es en cierto grado esta autenticidad que pretende el texto del personajeescritor la que nos permite bosquejar -en el plano de lo ficcional, claro está- la intimidad de este personaje $y$, junto a ella, su identidad. Tomando la lectura que Gallego Dueñas (26) hace de Jameson, podemos ver cómo esta tensión entre el texto que se inscribe en el ámbito de lo privado -la carta, el diálogo, la comunicación con un otro que excluye de los planes una lectura de un tercero- $y$, a su vez, el texto que queda abierto como posibilidad de lectura para otros -en tanto fijado en el lenguaje de una comunidad y también en el salto en el que el texto, a su vez, nos tiene como lectores- produce un pliegue que habilita el discurso de lo íntimo. Muchos elementos del texto operan como "tensores" (Gallego Dueñas 27) entre las dos polaridades que aparecen en Amado Señor. Por un lado, la carta íntima, y, por el otro, la escritura como acto público, como testimonio ficcional. Esta tensión -y muchas otras- no es ajena en lo absoluto al personaje que enuncia el texto que leemos: ¿¿Quién podría leer esto que te digo, si yo te lo digo a vos y a nadie más? Tal vez no lo lea nadie. $O$ tal vez lo lean como cuando se lee un testimonio. El testimonio de un diálogo con vos. El testimonio de una ocasión en la que escuchaste todo lo que se te decía" (32).

Este pliegue que surge y se nutre de estos tensores se ve reforzado por un conjunto de muchas otras tensiones que el personaje va sacando a flote a lo largo del texto: la oposición entre la vida y el destino (31), el equilibrio y el desequilibrio (13), el interés y el desinterés (55), la nada y el todo (75), la utilidad y la inutilidad (76), etc. El tema de la tensión no solo es explícito en el texto, sino que cada una de las tensiones se aborda desde la reflexión y desde la paradoja. El personaje se 
piensa siempre partícipe de una tensión que no se resuelve porque sencillamente no puede resolverse.

Preferiría darme directamente, o al menos darte forma y verte y ver en tus ojos la forma que me das, pero nada de eso es posible. Lo que sí sé es que todo este esfuerzo se tensa con la forma que tengo cuando no te hablo, que es una forma en la que vos no tenés nada que ver. Y que esa tensión es, finalmente, lo que busco: que la forma que vos me das se enfrente con la forma que tengo por hacer todas las cosas que hago y por ser las cosas que soy, por haber nacido en un lugar y no en otro, en una familia y no en otra, trabajar de una cosa y no de otra, tener unas ideas políticas y no otras. Es que la forma que vos me das cuando te hablo es solo para hablarte, pero después tiene efectos en la forma de mi vida, trata de arrastrar mi vida hacia vos, Sueño Olvidado, pero mi vida se resiste, afortunadamente, porque si no lo hiciera, ¿qué quedaría? (160-161).

Como puede verse, esta tensión irresoluble es también del orden de lo ontológico. La distancia entre la criatura y su creador es una distancia que permanece como tal; resolver esta distancia sería lo contrario a lo que el personaje-escritor parece buscar en el texto. Fundirse en el absoluto al que le escribe lo haría desaparecer del todo, lo borraría de un plumazo deshaciendo en un todo la identidad que, en constante desequilibrio, construye. Mantenerse diferente $-y$ en tensión- es lo que le permite conservar su individualidad. El otro polo de esta tensión se resolvería con el alejamiento, con el olvido del Amado Señor, algo a lo que el personaje no parece estar dispuesto.

Amado Señor es un texto marcado por la paradoja y construido entre diversas tensiones que se entrelazan, ya de un modo explícito en el discurso del personaje, ya de un modo implícito en la propia estructura dada por Katchadjian.

Me gustan las fábulas y las alegorías, pero no me gusta que estén dirigidas a enseñar alguna cosa específica. Creo que lo de la alegoría sin enseñanza lo tomé directamente de Kafka. Que no haya enseñanza crea una tensión: uno lee como si se la fueran a dar y no se la dan, y se queda dando vueltas, perdido, como los personajes mismos (Contré párr. 23). 
En su doble naturaleza de búsqueda - de una individualidad que tiende hacia la figura de su creador- y de testimonio, Amado Señor resulta un texto profundamente inscrito en una escritura del yo. El personaje-escritor reconoce la distancia prudencial que debe mantener con el enunciatario para no perderse, pero al mismo tiempo no puede evitar fundirse en él, disolverse y recrearse continuamente manteniendo -paradójicamente, aunque evidente en las marcas del relato- su individualidad: "Aunque tengo que decir que cuando te hablo me siento en riesgo físico: riesgo de destrucción. Porque, para hablarte, me destruyo para así poder reconstruirme hablándote. O me destruís vos para que yo me reconstruya" (140).

La vastedad del objeto discursivo y la aparente transparencia con que el personaje-escritor se pronuncia en el texto conducen al lector a recorrer variados escenarios narrativos -aparentes digresiones- que se intercalan con la voz reflexiva que busca dilucidar $-\mathrm{y}$, al mismo tiempo, evitar- el pleno conocimiento del Amado Señor. Es esta distancia tensional la que permite que el personajeescritor pueda seguir buscando $-y$ escribiendo- continuamente, como si se desplazara siempre en pos de un horizonte: aunque inalcanzable por definición, no frena el paso del que camina; atravesando el territorio el recorrido existe aún frente a la imposibilidad de la empresa final. El proceso es infinito y podría seguir; las metáforas y las paradojas posibles son tan inagotables como el lenguaje.

No puedo entender tu forma porque cambiás cada vez que te miro y te hablo: tomás mis palabras y las engullís y te modificás y me devolvés las palabras modificadas. Por eso no sé qué es lo que digo cuando te hablo, pero sí sé, cuando te hablo, qué tengo que decir para hablarte, porque sé que palabras son en cada momento las que me pedís, aunque en realidad no lo sepa en ningún momento. Porque todo esto ocurre instantáneamente sin que pase ni una fracción de segundo: hablo y se produce todo este proceso que solo puedo intuir viendo las palabras. ¿Qué veo? Veo que en apariencia las palabras son las mismas que dije, pero que al mismo tiempo son completamente distintas, porque no las dije yo sino vos. (...) No es perfecto ni imperfecto, es tenso. Es una cuerda tensada que vibra 
no se sabe por qué. Pero vibra y hace sonar notas que aparecen y quedan escritas (71-72).

De algún modo, el personaje-escritor es consciente de todo este juego de tensiones que detallamos más arriba. Para él la paradoja es tangible, pero este hecho -y la conciencia de este hecho- no detiene su pluma. La escritura es de este modo una búsqueda, un tender hacia el Amado Señor, que es siempre eso mismo, una tendencia. Es por esto que las tensiones no se resuelven: son un fin en sí mismas. En ese volcarse a la escritura dialógica, el personaje-escritor se relee y ahí radica el fruto de ese diálogo: en un intento por conocer al otro a quien le escribe, el personaje-escritor se sumerge en un diálogo que no es otro que el de la reflexión sobre el propio discurso y sobre la propia persona.

\section{Referencias}

Agustín, Santo (Obispo de Hipona). Confesiones. Alicante: Biblioteca Virtual Miguel de Cervantes, $2002 . \quad$ Web. http://www.cervantesvirtual.com/nd/ark:/59851/bmc639p3

Borges, Jorge Luis. "La esfera de Pascal". Cuentos completos. Buenos Aires: Debolsillo. 2005. Impreso.

Contré, Guillaume. "Dar vueltas, perdido, y agradecer a los muertos. Entrevista con Pablo Katchadjian realizada por Guillaume Contré". Entr. Pablo Katchadjian. Penúltima. Una revista literaria, septiembre 2015. Web. $\square$ http://revistapenultima.com/dar-vueltas-perdido-agradecer-los-muertosentrevista-pablo-katchadjian-realizada-guillaume-contre/ $\square$

De Man, Paul. "La autobiografía como des-figuración". Suplementos Anthropos. 29. 1991: 113-118. Web.

Gallego Dueñas, Francisco. "Cartografías y geografías del secreto: el secreto como espacio-tiempo social". Intersticios. 9, 1. 2015: 17-39. Web. 
Musitano, Julia. "La autoficción: una aproximación teórica. Entre la retórica de la memoria y la escritura de recuerdos". Actas Literarias de la Universidad de Concepción. Jul. 52. 2016: 103-123. Web.

Kafka, Franz. "Carta al padre". La metamorfosis-Carta al padre. Boulogne: Cántaro, 2017. Impreso.

Katchadjian, Pablo. Amado señor. Buenos Aires: Blatt y Ríos, 2020. Impreso.

Politzer, Heinz. "Franz Kafka's Letter to His Father". En: The Germanic Review, Culture Theory, 28:3, 165-179. 1953. Digital.

Sztajnszrajber, Darío. "Entrevista a Pablo Katchadjian por su libro Amado señor". Entr. Pablo Katchadjian. Radio CUT. Lo Intempestivo, 9 de octubre de 2020. Web. https://ar.radiocut.fm/audiocut/entrevista-a-pablo-katchadjian-por-sulibro-amado-senor/ $\square$ 